Original Article

\title{
Effect of Adipose Tissue-Derived Stem CeII Transplantation and Six Weeks of Aerobic Exercise on FNDC5 and Irisin Levels in Streptozotocin- Induced Diabetic Rats
}

Mehdi Nasiraei

(PhD Student) Department of Sport Physiology, Sari Branch, Islamic Azad University, Sari, Iran

\section{Abdolreza Jafari chashmi \\ (PhD) Department of Sport Physiology, Sari Branch, Islamic Azad University, Sari, Iran \\ Seyd Abdollah Hashemvarzi \\ (PhD) Department of Sport Physiology, Sari Branch, Islamic Azad University, Sari, Iran \\ Corresponding author: Abdolreza Jafari \\ E-mail: Jafarychashmy@gmail.com Tel: +981133213431 \\ Address: Department of Sport Physiology, Sari Branch, Islamic Azad University, Sari, Iran \\ Received: 2020/06/7 \\ Revised: $2020 / 07 / 18$ \\ Accepted: 2020/07/18 \\ (c) (i) \&}

This work is licensed under a Creative Commons Attribution 4.0 License.

DOI: $0.29252 / \mathrm{mlj} .14 .6 .34$

\begin{abstract}
Background and objectives: It has been suggested that irisin and fibronectin type III domain-containing protein 5 (FNDC5) can increase energy expenditure, promote weight loss and improve insulin resistance in diabetic patients by affecting white and brown adipose tissues. In this study, we investigate effect of adipose tissue-derived stem cell transplantation and six weeks of aerobic exercise on FNDC5 and irisin levels in streptozotocin-induced diabetic rats.
\end{abstract}

Methods: Forty-eight rats (weighing 220-240 $\mathrm{g}$ and aged nine weeks) were divided into six groups of control, sham, diabetes control, diabetes + exercise, diabetes + stem cell and diabetes + exercise + stem cell. The exercise group ran on running wheel at intensity of $60-70 \% \mathrm{VO}_{2} \max$, five days a week for six weeks. Next, $1.56 \times 10^{6}$ stem cells extracted from human adipose tissue were injected into the tail vein of streptozotocin-induced diabetic rats. Finally, FNDC5 and irisin plasma levels of the mice were measured using enzymelinked immunosorbent assay kits.

Results: FNDC5 and irisin levels reduced significantly in the diabetes control group $(\mathrm{P}=0.0001)$. FNDC5 levels in the diabetes + exercise + stem cell and the exercise group increased significantly compared to the diabetes control group $(\mathrm{P}=0.0001)$. The irisin level in the diabetes + stem cell + exercise group, exercise group and stem cell group increased significantly compared to the diabetes control group $(\mathrm{P}=0.0001)$.

Conclusion: The results indicate that aerobic exercise program and stem cell therapy alone and combined can significantly increase plasma irisin levels. Given the favorable effects of adipose tissue-derived stem cell injection and aerobic exercise on FNDC5 and irisin levels, this strategy could be further evaluated in coping with the adverse effects of diabetes on metabolism and aging.

Keywords: Aerobic exercise, Adipose tissue-derived stem cell, FNDC5, Irisin, Diabetes 


\section{INTRODUCTION}

Diabetes is a metabolic disorder characterized by hyperglycemia due to a defect in insulin secretion, insulin function or both. The disease is associated with endocrine disorders and metabolic complications (1). Diabetes mellitus has been one of the chief causes of death in the United States over the past few decades. More than half of diabetic individuals are unaware of their condition, which could be a reason for the increased diabetes-associated mortality rates (2). Longterm studies on diabetics demonstrate a $99 \%$ and $40-50 \%$ reduction in beta cell activity in type 1 diabetes and type 2 diabetes, respectively $(3,4)$. Diabetes mellitus is involved in the metabolism of brain amyloid and the tau protein. Changes in insulin and glucose hemostasis at the peripheral parts of the body may affect the function of insulin and its receptor, thus leading to increased amyloidbeta oligomerization and tau hyperphosphorylation (5). According to research, irisin and fibronectin type III domain-containing protein 5 (FNDC5) are newly-identified proteins that can increase energy expenditure, promote weight loss and improve insulin resistance in diabetic patients by affecting white and brown adipose tissues (6). Regular physical activity, proper nutrition, limited consumption of alcohol and tobacco products and stress reduction for the benefit of mental health are some of the national health aims pursued by developed countries (7). Although regular physical activity improves the human body's functioning, comprehensive results are needed to further support this claim (8). Several hormones secreted from the adipose tissue and skeletal muscles are responsible for the regulation of energy expenditure and prevention of weight gain and insulin resistance. Irisin, as a unique example of these hormones, is associated with energy homeostasis and subsequently obesity. It exerts considerable direct effects on adipose tissue and is a potential indicator of myocardial infarction (9). This hormone is secreted into the bloodstream through skeletal muscle contraction after cleavage from FNDC5 (9). Studies have shown that regular exercise has a positive impact on irisin and
FNDC5 levels through increased energy metabolism $(10,11)$. In this regard, a study showed that 10 weeks of endurance training results in a two-fold increase in FNDC5 levels in human subjects (12). Both irisin and FNDC5 are involved in the beneficial effects of exercise on adipose tissue of humans and rodents (13). Sanchez et al. reported that irisin and FNDC5 could increase energy expenditure and maintain normoglycemia (14). In contrast, it has been shown that circulating irisin levels are reduced in trained individuals (15). Irisin is a signaling protein released from the skeletal muscles after proteolysis of the FNDC5 protein through overexpression of $P P A R-\gamma$ and uncoupling protein-1 gene (UCPI) and other genes associated with the browning of white adipose tissue (16). The level of irisin after exercise varies significantly in mice and human subjects (17). Brown adipose tissue plays a thermogenic role due to UCPI expression and increased mitochondrial capacity (18). As a non-pharmacological treatment, exercise plays an influential role in regulating and reducing inflammatory cytokines associated with the production of pancreatic beta cells (19-21). It has been also indicated that both short-term and long-term exercise can decrease blood glucose concentration and insulin resistance and increase beta cell mas through the process of hyperplasia (22-25). Although there is a consensus about the significance of physical activity, the type of exercise to render weight loss and health improvement is not yet clear. However, persistent aerobic exercise at moderate-intensity has been recommended to achieve the best metabolic adaptations (26, 27).

Stem cell therapy is a relatively novel method proposed for the compensation of lost cells (28-30). An interesting source of these cells are mononuclear stem cells derived from adipose tissue that have faster growth rates compared to umbilical cord and bone marrow stem cells $(31,32)$. In this study, we investigate the interactive effects of aerobic exercise and intravenous injection of adipose tissue-derived stem cells on FNDC5 and irisin

\section{MATERIALS AND METHOS}

The present study was approved by the National Committee for Ethics in Biomedical Research. A total of 48 adult eight-week-old male Wistar rats weighing approximately 
220-240 grams were provided. The rats were kept in the rodent laboratory of the Islamic Azad University of Sari for a week to adapt to the environment. All laboratory procedures were in accordance with the standards for the care and use of laboratory animals. At nine weeks of age and after acquaintance with running wheel, the animals were randomly assigned to six groups of healthy control, sham, diabetes control, diabetes + exercise, diabetes + stem cell and diabetes + exercise + stem cell. All groups had ad libitum access to water and food. The animals were kept in groups of four, at temperature of $20-25{ }^{\circ} \mathrm{C}$, under $12: 12 \mathrm{~h}$ light-dark cycle with a relative humidity of $45-55 \%$.

To induce diabetes in rats, the subjects received intravenous injection of streptozotocin $(60 \mathrm{mg} / \mathrm{kg})$. Blood samples were collected from the subjects' tail $72 \mathrm{~h}$ after the induction of diabetes. Blood sugar was measured with a glucometer (GM110, Bionime, Switzerland). Subjects with a fasting blood sugar of more than $250 \mathrm{mg} / \mathrm{dl}$ were considered as diabetic (30) (Table 1).

To obtain adipose tissue stem cells, adipose samples were taken from the abdominal area of patients referred to the surgery ward of AlZahra hospital in Isfahan (Iran) for liposuction procedure. The collected tissue samples were placed in a sterile container and were transferred to the laboratory at room temperature. The tissues were washed with phosphate buffer saline (PBS) containing penicillin-streptomycin four times to make sure the solution is free from blood. The tissues were then digested by collagenase- 1 for 90 minutes at $37{ }^{\circ} \mathrm{C}$ to separate cells. Next, enzymatic activity and cell plaque were obtained. The remaining red blood cells were lyzed with tris-buffered ammonium chloride. The resulting cells were counted, cultured in a cell culture flask and finally injected into the subjects after fluorescence identification. Cellular expression of CD29 and CD90 was evaluated to determine the phenotype characteristics of the adipose-derived stem cells $(30,33)$. After induction of anesthesia by intraperitoneal injection of a mixture of $10 \%$ ketamine $(50 \mathrm{mg} / \mathrm{kg})$ and $2 \%$ xylazine $(10$ $\mathrm{mg} / \mathrm{kg}$ ), the tails were kept in warm water for one minute to dilate the vascular vessels and thus the vein. Next, after washing the cells with PBS, about $1.56 \times 10^{6}$ stem cells extracted from the human adipose tissue were injected into the tail vein of diabetic rats with the aid of insulin syringes (30).

The aerobic exercise protocol consisted of running at speed of $10-18 \mathrm{~m} / \mathrm{min}$ (equivalent to $60-70 \% \mathrm{VO}_{2} \max$ ) five days a week for six weeks. The speed and duration of exercise increased gradually from $10 \mathrm{~m} / \mathrm{min}$ for $10 \mathrm{~min}$ in the first week to $17-18 \mathrm{~m} / \mathrm{min}$ for $30 \mathrm{~min}$ in the fifth week (34). At the end of the exercise program, the rats were first anesthetized with a 60:40 ratio of ketamine xylazine. Then, $10 \mathrm{ml}$ of blood were collected from the right ventricle into a tube containing EDTA using a syringe soaked in EDTA. The collected blood samples were immediately centrifuged at $1,500 \mathrm{rpm}$ for $10 \mathrm{~min}$ to separate plasma. The collected plasma samples were stored in a freezer at $-80^{\circ} \mathrm{C}$ for further measurements. The concentration of FNDC5 and irisin were measured by commercial enzyme-linked immunosorbent assay kits (Hangzhou Co., China) with a sensitivity coefficient of 0.5 $\mathrm{pg} / \mathrm{mg}$.

Normality of data was confirmed by the Kolmogorov-Smirnov test. Data were analyzed using one-way analysis of variance (ANOVA) and the Tukey's range test. All statistical analyses were carried out in SPSS (version 20) at significance of 0.05 .

Table 1. The average blood sugar of the groups and confirmation of diabetes in the model groups

\begin{tabular}{cccc}
\hline Groups & $\begin{array}{c}\text { Average blood } \\
\text { sugar (mg/dl) }\end{array}$ & $\begin{array}{c}\text { Standard } \\
\text { deviation }\end{array}$ & Number of rats \\
\hline Control & 113.28 & 4.42 & $\mathbf{8}$ \\
\hline Sham & 114.42 & 4.23 & $\mathbf{8}$ \\
\hline Diabetes control & 334.71 & 11.48 & $\mathbf{8}$ \\
\hline $\begin{array}{c}\text { Exercise + Diabetes } \\
\text { Diabetes + Stem } \\
\text { Cell }\end{array}$ & 293.57 & 11.58 & $\mathbf{8}$ \\
\hline $\begin{array}{c}\text { Diabetes + Stem } \\
\text { Cell + Exercise }\end{array}$ & 334.85 & 4.70 & $\mathbf{8}$ \\
\hline
\end{tabular}


The irisin level in the diabetes control group decreased significantly compared to the healthy control group $(\mathrm{P}=0.0001)$. Moreover, the irisin level increased significantly in the exercise + stem cell group compared with the healthy control and diabetes control groups $(\mathrm{P}=0.0001)$ (Table 3). The irisin level was also considerably higher in the diabetes + exercise group than in the diabetes control group $(\mathrm{P}=0.0001)$. On the other hand, in the diabetic + stem cell group, there was a significant increase in the irisin level compared to the diabetes control group ( $\mathrm{P}=0.0001)$ (Figure 2).

\section{RESULTS}

The FNDC5 level in the diabetes control group decreased significantly compared to the healthy control group $(\mathrm{P}=0.0001)$ (Table 2$)$. In addition, FNDC5 level increased significantly in the exercise + stem cell group compared with the diabetes control group $(\mathrm{P}=0.0001)$ (Figure 1).

Table 2. Mean level of FNDC5 in the study groups

\begin{tabular}{ccccc}
\hline Group & $\begin{array}{c}\text { Mean } \\
(\mathbf{n g} / \mathbf{m l})\end{array}$ & $\begin{array}{c}\text { Standard } \\
\text { deviation }\end{array}$ & Minimum & Maximum \\
\hline Control & 2.42 & 0.51 & 1.90 & $\mathbf{2 . 9 0}$ \\
Sham & 2.06 & 0.46 & 1.70 & $\mathbf{2 . 8 0}$ \\
Diabetes control & 1.35 & 0.41 & 1.10 & $\mathbf{2 . 0 0}$ \\
$\begin{array}{c}\text { Exercise }+ \\
\text { Diabetes }\end{array}$ & 1.98 & 0.39 & 1.20 & $\mathbf{2 . 5 0}$ \\
$\begin{array}{c}\text { Diabetes }+ \\
\text { Stem Cell }\end{array}$ & 1.71 & 0.50 & 1.30 & $\mathbf{1 . 9 0}$ \\
$\begin{array}{c}\text { Diabetes + } \\
\text { Exercise }+ \\
\text { Stem Cell }\end{array}$ & 2.00 & 0.47 & 1.90 & $\mathbf{2 . 3 0}$ \\
\hline
\end{tabular}

Table 3. Mean level of irisin in the study groups

\begin{tabular}{|c|c|c|c|c|}
\hline Group & $\begin{array}{c}\text { Mean } \\
(\mathbf{n g} / \mathbf{m l})\end{array}$ & $\begin{array}{c}\text { Standard } \\
\text { deviation }\end{array}$ & Minimum & Maximum \\
\hline Control & 71.00 & 7.23 & 65.00 & 76.00 \\
\hline Sham & 70.12 & 6.70 & 65.00 & 74.00 \\
\hline Diabetes control & 50.62 & 4.54 & 45.00 & 53.00 \\
\hline Exercise + Diabetes & 68.00 & 5.21 & 63.00 & 73.00 \\
\hline Diabetes + Stem Cell & 62.87 & 5.01 & 60.00 & 67.00 \\
\hline $\begin{array}{c}\text { Diabetes + Exercise + } \\
\text { Stem Cell }\end{array}$ & 69.12 & 5.23 & 63.00 & 73.00 \\
\hline
\end{tabular}

Figure 1. Changes in the mean FNDC5 level $(\mathrm{ng} / \mathrm{ml})$ in the study groups. * indicates significant difference with the diabetes control group. \# indicates significant difference with the healthy control group.

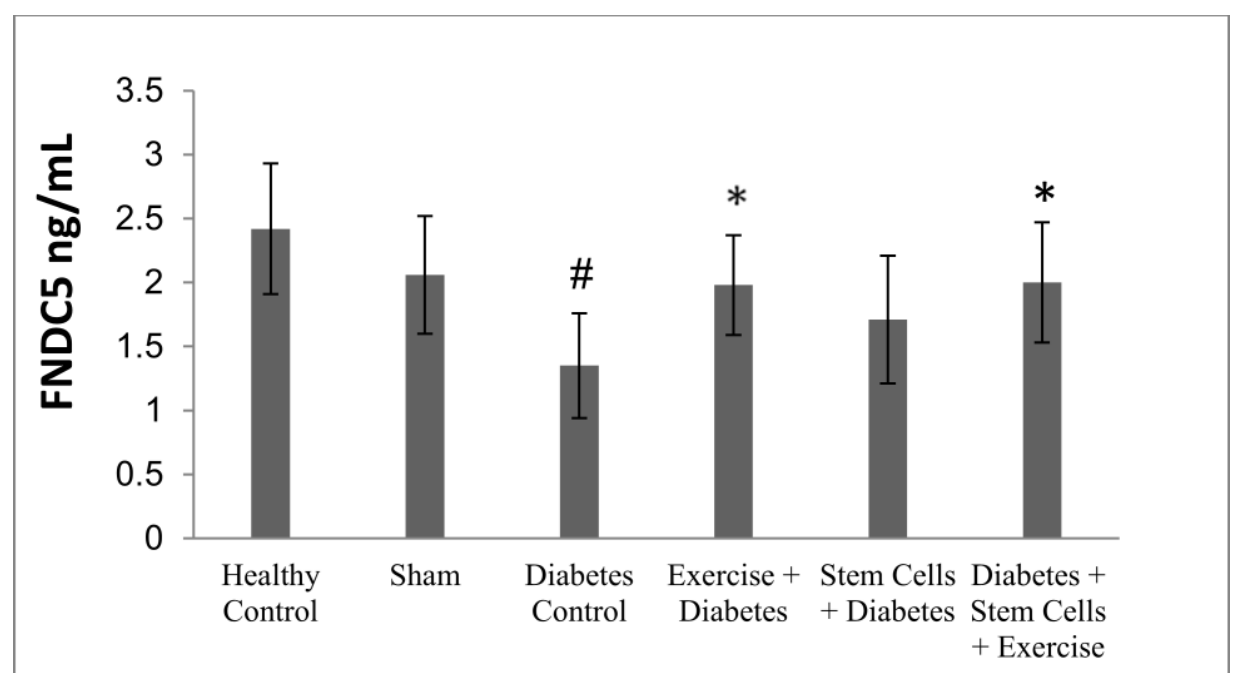


Figure 2. Changes in the mean irisin level $(\mathrm{ng} / \mathrm{ml})$ in the study groups. * indicates significant difference with the diabetes control group. \# indicates significant difference with the healthy control group

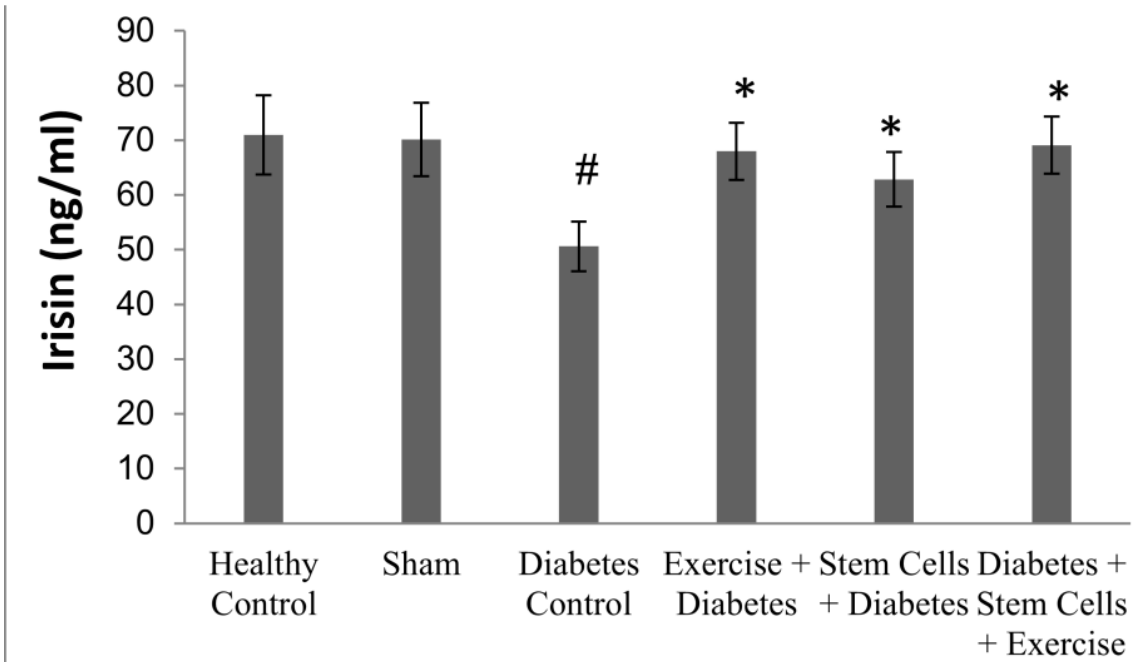

\section{DISCUSSION}

The main purpose of the study was to investigate the combined effect of exercise along with adipose-derived stem cell injection on diabetic rats. Based on the results, plasma levels of FNDC5 and irisin increased significantly in diabetic mice after the sixweek training and adipose tissue-derived stem cells injection. Moreover, the exercise program and stem cell therapy alone and combined significantly increased plasma irisin level compared to the diabetes control group. On the other hand, the FNDC5 levels increased significantly in the exercise group and slightly in the exercise + stem cell group. Thus, it seems that each intervention alone could be a protective factor against the adverse effects of diabetes. Consistent with the results of the present study, it has been shown that 10 weeks of endurance training results in a 2 -fold increase in FNDC5 level that in turn affects energy metabolism (12). In a study by Roca et al., short-term training stimulated FNDC5 secretion in subcutaneous and visceral adipose tissues. It was also observed that white adipose tissue could significantly reduce FNDC5 secretion in fasting animals. Interestingly, white adipose tissue of obese animals oversecreted this hormone, which might suggest some kine of resistance because $72 \%$ of circulating FNDC5/irisin were previously attributed to muscle secretion. Spiegelman et al. determined that irisin has direct and significant effects on adipose tissue. They also concluded that the exercise-induced irisin secretion promotes browning of white adipose tissue (16). Sanchez et al. reported that irisin and FNDC5 released from skeletal muscles could increase energy expenditure and maintain normoglycemia (36).

In 2013, Wilson et al. revealed that stem cells isolated from adipose tissue could be differentiated to various cell types to compensate damages to the neurons, cartilage and cardiac cells (37). In a previous study, infection of human adipose tissue-derived stem cells into type 2 diabetic rats resulted in a decrease in blood sugar (38). In the present study, FNDC5 level slightly increased following stem cell therapy, which could be related to the injection-induced stress. In a study on the effects of umbilical cord blood stem cell injection on diabetes, blood sugar level and insulin resistance in adipose tissue of diabetics decreased significantly compared to the control group (39). This can be related to the effects of the milieu in which the stem cells are infused that resulted in secretion of vascular growth factors and cytokines involved in the autocrine or paracrine signaling (40). In line with the present study, another study demonstrated that adipose tissue-derived stem cell transplantation could repair corpus striatum mainly through an increase in vascular endothelial growth factor levels and the angiogenesis process (41). 
Increase in vascularity of adipose tissue can in turn increase the access of adipose tissue to metabolic hormones, oxygen and nutrients as well as increased insulin sensitivity.

\section{CONCLUSION}

Given the favorable effects of adipose tissue-derived stem cell injection and exercise on FNDC5 and irisin levels, this strategy could be further evaluated in coping with the adverse effects of diabetes on metabolism and aging.

\section{ACKNOWLEDGMENTS}

We would like to thank all those who helped us in this research.

\section{CONFLICT OF INTEREST}

The authors declare that there is no conflict of interest regarding publication of this article.

\section{REFERENCES}

1.Havilah P, Pandit Vinodh B, Durga Prasad K Adenosine Deaminase Activity in Type-2 Diabetes Mellitus - An Independent Marker of Glycemic Status and Stimulator of Lipid Peroxidation. Int $\mathrm{J}$ Chem and Life Sciences. 2013; 02(06): 1175-1178. doi: 10.1186/s12902-018-0284-9.

2. Glovaci D, Fan W, Wong ND. Epidemiology in diabetes mellitus and cardiovascular disease. Curr Cardiol Rep. 2019; 21(4): 21. doi: 10.1007/s11886-0191107-y.

3. Meier JJ, Bhushan A, Butler AE, Rizza RA, Butler PC. Sustained beta cell apoptosis in patients with longstanding type 1 diabetes: indirect evidence for islet regeneration? Diabetologia. 2005; 48(11): 2221-8. doi: 10.1007/s00125-005-1949-2.

4. Butler AE, Janson J, Bonner-Weir S, Ritzel R, Rizza RA, Butler PC. Beta-cell deficit and increased beta-cell apoptosis in humans with type 2 diabetes. Diabetologia. 2005; 48(11): 2221-8.doi: 10.1007/s00125-005-1949-2.

5. Roriz-Filho JS, Sá-Roriz TM, Rosset I, Camozzato AL, Santos AC, Chaves MLF, et al. (Pre)diabetes, brain aging, and cognition. Biochimica et Biophysica Acta. 2009; 1792: 432-443.

6. Jahangard A, Hamedinia M, Hosseini Kakhk A, Jafari A, Salehzadeh K. The effects of short-term supplementation of garlic extract on oxidative stress indicators in times of resting and exhaustive exercising on male football players. Iranian Journal Of

Endocrinology And Metabolism (Ijem). 2013; 15 (1): 7885.

7. Khosrow E, Ahmadizad S, Ghanimati R, Bagheri A, Sheikhi S, Ghanimati M. The effect of endurance training and garlic consumption on maximum oxygen consumption (VO2max) of inactive men. Applied Research in Management and Biological Sciences in Sports. 2012; 2: 18-11.

8. Johari H, Zamani Z, Mokhtari M, Hemayatkhah V, Jamali H, Yazdani M. Evaluation of the effect of garlic extract on eliminating lead poisoning in all infants of rats. Journal of Fasa University of Medical Sciences. 2014; 1: 98-90.
9. Shirzad H, Taji F, Pilehvarian AA, Hosseini SM, Rafieian Kopaei M. The preventive and therapeutic effects of fresh garlic extract and aerial parts on the growth of fibrosarcoma cells in mice. Journal of Shahid Sadoughi University of Medical Sciences and Health Services. 2012; 20(83): 133-141.

10. Finkelstein J, Joshi A, Hise MK. Association of physical activity and renal function in subjects with and without metabolic syndrome: a review of the Third National Health and Nutrition Examination Survey (NHANES III). Am J Kidney Dis. 2006; 48(3): 372-82. doi: 10.1053/j.ajkd.2006.05.013.

11. Johansson K, Neovius M, Hemmingsson E. Effects of anti-obesity drugs, diet, and exercise on weight-loss maintenance after a very-low-calorie diet or low-calorie diet: a systematic review and meta-analysis of randomized controlled trials. Am J Clin Nutr. 2014; 99(1): 14-23. doi: 10.3945/ajen.113.070052.

12. Ormsbee MJ, Thyfault JP, Johnson EA, Kraus RM, Choi MD, Hickner RC. Fat metabolism and acute resistance exercise in trained men. J Appl Physiol . 2007; 102(5): 1767-72. doi: 10.1152/japplphysiol.00704.2006.

13. José María Moreno-Navarrete, Francisco Ortega, Marta Serrano, Ester Guerra, Gerard Pardo, Francisco Tinahones, et al. Irisin is expressed and produced by human muscle and adipose tissue in association with obesity and insulin resistance. J Clin Endocrinol Metab. 2013; 98(4): E769-78. doi: 10.1210/jc.2012-2749.

14. Sanchis-Gomar F, Lippi G, Mayero S, Perez-Quilis C, García-Giménez JL. Irisin: a new potential hormonal target for the treatment of obesity and type 2 diabetes. $\mathrm{J}$ Diabetes. 2012; 4(3): 196.doi: 10.1111/j.17530407.2012.00194.x.

15. Polyzos SA, Kountouras J, Shields K, Mantzoros CS. Irisin: a renaissance in metabolism? Metabolism. 2013; 62(8): 1037-44.doi: 10.1016/j.metabol.2013.04.008.

16. Boström P, Wu J, Jedrychowski MP, Korde A, Ye L, Lo JC, et al. A PGC1- $\alpha$-dependent myokine that drives brown-fat-like development of white fat and thermogenesis. Nature. 2012; 481(7382): 463-8.doi: 10.1038/nature10777.

17. Little JP, Safdar A, Wilkin GP, Tarnopolsky MA, Gibala MJ. A practical model of low-volume highintensity interval training induces mitochondrial biogenesis in human skeletal muscle: potential mechanisms. The Journal of Physiology. 2010; 588(Pt 6): 1011-1022.

18. Handschin C, Spiegelman BM. The role of exercise and $P G C-1 a$ in inflammation and chronic disease. Nature. 2008; 454(7203): 463-469.

19. Hamidi Perchikolaei SO, Falah Mohamadi Z, Hajizadeh Moghadam A. The effect of treadmill running with consumption of vitamin D3 on NGF levels in Parkinsonian rat's striatum. Sport Physiology. 2016; 8 (29): 91-102.

20. Tang Z, Yuan L, Gu C, Liu Y, Zhu L. Effect of exercise on the expression of adiponectin $m R N A$ and GLUT4 mRNA in type 2 diabetic rats. J Huazhong Univ Sci Technolog Med Sci. 2005; 25(2): 191-193.

21. De Salles Bf, Simão R, Fleck SJ, Dias I, KraemerAguiar LG, Bouskela E. Effects of resistance training on cytokines. Int J Sports Med. 2010; 31(7): 441-50. 
22. Sheu WH, Chang TM, Lee WJ, Ou HC, Wu CM, Tseng LN, et al. Effect of weight loss on proinflammatory state of mononuclear cells in obese women. Obesity (Silver Spring). 2008; 16(5): 1033-8.

23. Boulé NG, Haddad E, Kenny GP, Wells GA, Sigal RJ. Effects of exercise on glycemic control and body mass in type 2 diabetes mellitus: a meta-analysis of controlled clinical trials. JAMA. 2001; 286(10): 121827.

24. Tokmakidis SP, Zois CE, Volaklis KA, Kotsa K, Touvra AM. The effects of a combined strength and aerobic exercise program on glucose control and insulin action in women with type 2 diabetes. Eur $\mathrm{J}$ Appl Physiol. 2004; 92(4-5): 437-42.

25. Mojtaba E, Behboudi L. Effect of Acute and Chronic Exercise on Beta-Cell Function in Diabetic Patients. Knowledge \& Health. 2012; 6(4): 15-19.

26. Huh JY, Mougios V, Kabasakalis A, Fatouros I, Siopi A, Douroudos, II, et al. Exercise-induced irisin secretion is independent of age or fitness level and increased irisin may directly modulate muscle metabolism through AMPK activation. J Clin Endocrinal Metab. 2014; 99(11): E2154-61.

27. Tofighi A, Mohammadi Topuzabadi B. The effect of eight weeks high intensity interval training on plasma irisin and subcutaneous adipose tissue UCP-1 in male obese rat. Journal of Sport in Biomotor Sciences. 2016; 8(16): 62-69.

28. Pourheydar B, Shahi M, Farjah Gh H. Evaluation of Apoptosis In Hippocampal Cells of Rat Following Intravenous Injection of Bone Marrow Stromal Cells In Ischemia-Reperfusion Model. The Journal of Urmia University of Medical Sciences. 2014; 25(7): 597.

29. Guo F, Lv S, Lou Y, Tu W, Liao W, Wang Y, et al. Bone marrow stromal cells enhance the angiogenesis in ischemic cortex after stroke: involvement of notch signalling. Cell Biol Int. 2012; 36(11): 997-1004. doi: 10.1042/CBI20110596.

30. Moradi A, Mohammadi S, Hamidi Alamdari D. Effect of adipose tissue-derived stem cells on the control of the blood glucose level in diabetic rats. J Shahid Sadoughi Univ Med Sci. 2015; 23(8): 717-26.

31. Lock LT, Tzanakakis ES. Stem/Progenitor cell sources of insulin-producing cells for the treatment of diabetes. Tissue engineering. 2007; 13(7): 1399-412.
32. Krishna KA, Rao GV, Rao KS. Stem cell-based therapy for the treatment of Type 1 diabetes mellitus. Regenerative med. 2007; 2(2): 171-77.

33. Taha MF, Hedayati V. Isolation, identification and multipotential differentiation of mouse adipose tissue derived stem cells. Tissue \& cell. 2010; 42(4): 211-16.

34. Chae CH, Jung SL, An SH, Park BY, Wang SW, Cho $\mathrm{IH}$, et al. Treadmill exercise improves cognitive function and facilitates nerve growth factor signaling by activating mitogen-activated protein kinaselextracellular signal regulated kinase1/2 in the streptozotocin-induced diabetic rat hippocampus. Neuroscience. 2009; 164: 1665-1673.

35. Arturo Roca-Rivada, Cecilia Castelao, Lucía L Senin, María O Landrove, Javier Baltar, Ana Belén Crujeiras, et al. FNDC5/irisin is not only a myokine but also an adipokine. PLoS One. 2013; 8(4): e60563.doi: 10.1371/journal.pone.0060563.

36. Sanchis-Gomar F, Lippi G, Mayero S, Perez-Quilis C, García-Giménez JL. Irisin: a new potential hormonal target for the treatment of obesity and type 2 diabetes. $\mathrm{J}$ Diabetes 2012; 4(3): 196. doi: 10.1111/j.17530407.2012.00194.x.

37. Wilson B, Liotta LA, Petricoiniii E. Dynamic protein pathway activation mapping of adipose-derived stem cell differentiation implicates novel regulators of adipocyte differentiation. Molecular \& cellular proteomics: MCP. 2013; 12(9): 2522-35.

38. Garcia Villar-Cheda B, Sousa-Ribeiro D, RodriguezPallares J, Rodriguez-Perez AI, Guerra MJ, Labandeira$\mathrm{JL}$. Aging and sedentarism decrease vascularization and $V E G F$ levels in the rat substantia nigra. Implications for Parkinson's disease. Journal of Cerebral Blood Flow \& Metabolism. 2010; 29(2): 230-234.

39. Zhao Y, Mazzone T. Human cord blood stem cells and the journey to a cure for type 1 diabetes. Autoimmunity reviews. 2010; 10(2): 103-07.

40. Kang X, Huadong X, Sasa T, Xiaoyu Z, Zijun D, Li Z. Dopamine release from transplanted neural stem cells in Parkinsonian rat striatum in vivo. Pnas. 2014; 111(44): 15804-15809.

41. Hashemvarzi SA, Heidarianpour A. Preconditioning Effect of Aerobic Exercise with D3 Vitamin Consumption on VEGF Levels in the 6-OHDA Lesioned Parkinson's disease Rat Model. Sport Physiology. 2016; 8(30): 12942. [Persian]

\section{How to Cite:}

This paper should be cited as: Nasiraei M, Jafari A, Hashemvarzi SA. [Effect of Adipose Tissue-Derived Stem Cell Transplantation and Six Weeks of Aerobic Exercise on FNDC5 and Irisin Levels in Streptozotocin-Induced Diabetic Rats]. mljgoums. 2020; 14(6): 34-40. DOI: $0.29252 / \mathrm{mlj} .14 .6 .34$. 